\title{
The Effect of an Emollient Containing Urea, Ceramide NP, and Lactate on Skin Barrier Structure and Function in Older People with Dry Skin
}

\author{
Simon G. Danby ${ }^{a}$ Kirsty Brown ${ }^{a} \quad$ Tim Higgs-Bayliss $^{a} \quad$ John Chittock ${ }^{a}$ \\ Lujain Albenalia, b Michael J. Cork ${ }^{a-c}$ \\ ${ }^{a}$ Academic Unit of Dermatology Research, Department of Infection, Immunity and Cardiovascular Disease, \\ Faculty of Medicine, Dentistry and Health, University of Sheffield Medical School, b Paediatric Dermatology Clinic, \\ Sheffield Children's Hospital, and 'Department of Dermatology, Royal Hallamshire Hospital, Sheffield, UK
}

\section{Key Words}

Skin barrier $\cdot$ Emollient $\cdot$ Xerosis $\cdot$ Urea $\cdot$ Ceramide $\cdot$ Fourier transform infrared spectroscopy $\cdot$ Transepidermal water loss

\begin{abstract}
Xerosis affects up to $75 \%$ of older people and develops as a result of a skin barrier defect. Emollients are widely used to treat xerosis; however, there is limited understanding of the differences between them and their effects on the skin barrier in older people. This study aimed to compare the effect of a commercially available emollient containing $5 \%$ urea, ceramide NP and lactate (test emollient) to an alternative emollient without these additives (control emollient) on the properties of the skin barrier in older people. Two cohorts of 21 volunteers aged $>60$ years with dry skin were recruited. The first applied the test emollient to one forearm and no treatment to the other for 28 days. The second compared the test emollient to the control emollient observing the same parameters. Effects on the skin barrier were determined by measuring skin barrier function, hydration, skin surface $\mathrm{pH}$ and by analysing Fourier transform infrared spectra before and after treatment. A third cohort of 6 young adults was re-
\end{abstract}

\section{KARGER}

E-Mail karger@karger.com www.karger.com/spp

\section{The Author(s) \\ Published by S. Karger AG, Basel $1660-5527 / 16 / 0293-0135 \$ 39.50 / 0$}

This article is licensed under the Creative Commons AttributionNonCommercial-NoDerivatives 4.0 International License (CC BY NC-ND) (http://www.karger.com/Services/OpenAccessLicense) Usage and distribution for commercial purposes as well as any distribution of modified material requires written permission. cruited to investigate the effect of a single treatment with the test emollient on the molecular structure of the skin barrier at greater depths by employing the tape-stripping technique. The test emollient hydrated the skin to a significantly greater extent and for a longer period of time compared to the control emollient, an effect associated with a significant elevation of carboxylate groups (a marker of natural moisturizing factor content) within the stratum corneum. Furthermore, the test emollient imparted additional benefits to the structure and function of the skin barrier not exhibited by the control emollient. In conclusion, the test emollient addressed the pathological features of xerotic aged skin, supporting its use as first-line therapy for xerotic skin conditions in this population.

(C) 2016 The Author(s)

Published by S. Karger AG, Basel

\section{Introduction}

Worldwide the prevalence of xerosis increases with advancing age, affecting up to $75 \%$ of older people [1]. The development of xerotic conditions, such as atopic dermatitis $(\mathrm{AD})$, asteatotic eczema and winter xerosis, is associated with a skin barrier defect. This defect is char- 
Table 1. Emollient creams used in this study

\begin{tabular}{llll}
\hline Treatment & Manufacturer & Product $\mathrm{pH}$ & Ingredients \\
\hline $\begin{array}{l}\text { Control } \\
\text { emollient }\end{array}$ & $\begin{array}{l}\text { Aquamol cream } \\
\text { (Thornton \& Ross Ltd., } \\
\text { Huddersfield, UK) }\end{array}$ & $5.57 \pm 0.005$ & $\begin{array}{l}\text { Purified water, white soft paraffin, liquid paraffin, } \\
\text { cetearyl alcohol, PPG-5-ceteth 20, disodium } \\
\text { cocoamphodiacetate, polysorbate 60, sodium } \\
\text { chloride, chlorocresol, citric acid monohydrate }\end{array}$ \\
\hline $\begin{array}{l}\text { Test } \\
\text { emollient }\end{array}$ & $\begin{array}{l}\text { Balneum cream } \\
\text { (Almirall Hermal GmbH, } \\
\text { Reinbek, Germany) }\end{array}$ & $4.73 \pm 0.002$ & $\begin{array}{l}\text { Urea 5\%, ceramide NP, aqua, glycine soya oil, } \\
\text { propylene glycol, cetearyl alcohol, liquid paraffin, } \\
\text { isohexadecane, sodium lactate, lactic acid, PEG-20 } \\
\text { stearate, polysorbate } 60, \text { squalane, stearic acid, } \\
\text { disodium EDTA, lecithin, tocopherol, ascorbyl } \\
\text { palmitate, hydrogenated palm glyceride citrate }\end{array}$ \\
\hline
\end{tabular}

acterized by reduced natural moisturizing factor [NMF, comprising sodium pyrrolidone carboxylic acid (PCA), urea and lactate amongst others] and abnormal levels of intercellular lipids (cholesterol, ceramides and free fatty acids) in the stratum corneum (SC) [2-5]. Additionally, the aged skin barrier recovers more slowly after exposure to irritants [6].

The growing recognition that xerotic skin conditions arise primarily as a result of a defective skin barrier calls for a greater appreciation of the effect of topical products on this barrier $[7,8]$. A paucity of evidence on the mechanistic effects of emollients has led many to believe that emollients are all the same. We, and others, have demonstrated however that emollients have very different effects on the skin barrier depending on their formulation [9, 10]. For example, some optimally designed emollients containing humectants ameliorate skin dryness and reduce the severity of skin inflammation [1113]. In stark contrast, aqueous cream, containing the harsh anionic surfactant sodium lauryl sulphate (SLS) and no humectant, was found to damage the skin barrier [14-17], an effect linked to high rates of adverse reactions and exacerbation of AD symptoms [18]. In response to growing evidence and improvements in emollient formulation, a recent consensus statement by health care professionals highlighted the need to differentiate emollients based on their mechanism of action [19]. The aim of this study was to directly compare the effect of an emollient cream, available for prescription in the UK, containing the skin-moisturizing factors urea, ceramide NP (previously ceramide 3 ), and lactate (test emollient), to an emollient cream without these additives (control emollient) in volunteers with xerosis aged over 60 years.

\section{Material and Methods}

\section{Subjects}

Three cohorts of volunteers were recruited. Volunteers scored their skin dryness on a 5-point scale from 1 (no dryness) to 5 (severe dryness with cracking and lifting scales). Cohort 1 consisted of 21 volunteers (17 women) with dry skin (mean score 3 ) and a mean age of 69 (60-89) years. Eight participants (38\%) reported previously having AD. Cohort 2 comprised 6 volunteers (4 women) with healthy skin (no history of skin conditions or atopy, mean skin dryness score 0 ) and a mean age of 33 (21-45) years. This separate population (cohort 2 ) with no age restriction was recruited for practical reasons due to the length of the measurement sessions and the intensity of measurements. For cohort 3, 21 volunteers (14 women) with dry skin (mean score 3 ) and a mean age of $68(60-79)$ years were recruited, 18 of whom completed the study. Three volunteers withdrew for reasons unrelated to the study. Six participants (33\%) reported a previous history of AD. Recruitment was open to males and females with a Fitzpatrick skin type of I-IV. Exclusion criteria consisted of the use of systemic or topical antiinflammatory medication in the 6 months leading up to the study, pregnancy, breast-feeding, and being under the age of 18 . Volunteers refrained from using topical products (except the study preparation as directed) on the treatment sites for $\geq 7$ days prior to participation and for the duration of the study.

\section{Treatment}

There were 2 test sites per volunteer, one on each forearm (volar side, $3 \mathrm{~cm}$ below elbow flexure to $3 \mathrm{~cm}$ above the wrist). Cohorts 1 and 3 undertook 28-day forearm-controlled observer-blind studies involving self-treatment with the test emollient (Balneum cream, table 1) and/or the control emollient (Aquamol cream, table 1). In essence cohort 1 undertook a direct comparison of the test emollient to untreated skin, and cohort 3 undertook a direct comparison of the test emollient to a reference emollient. The participants in cohort 1 treated one forearm with 2-fingertip units $(1.24 \pm 0.127 \mathrm{~g})$ of test emollient and the other forearm with no treatment (randomized) twice daily for 28 days. Following the cessation of treatment (12-20 h) the biophysical properties of the test sites were assessed to determine the effect of the treatment on the underlying condition of the skin barrier (not their transient occlu- 


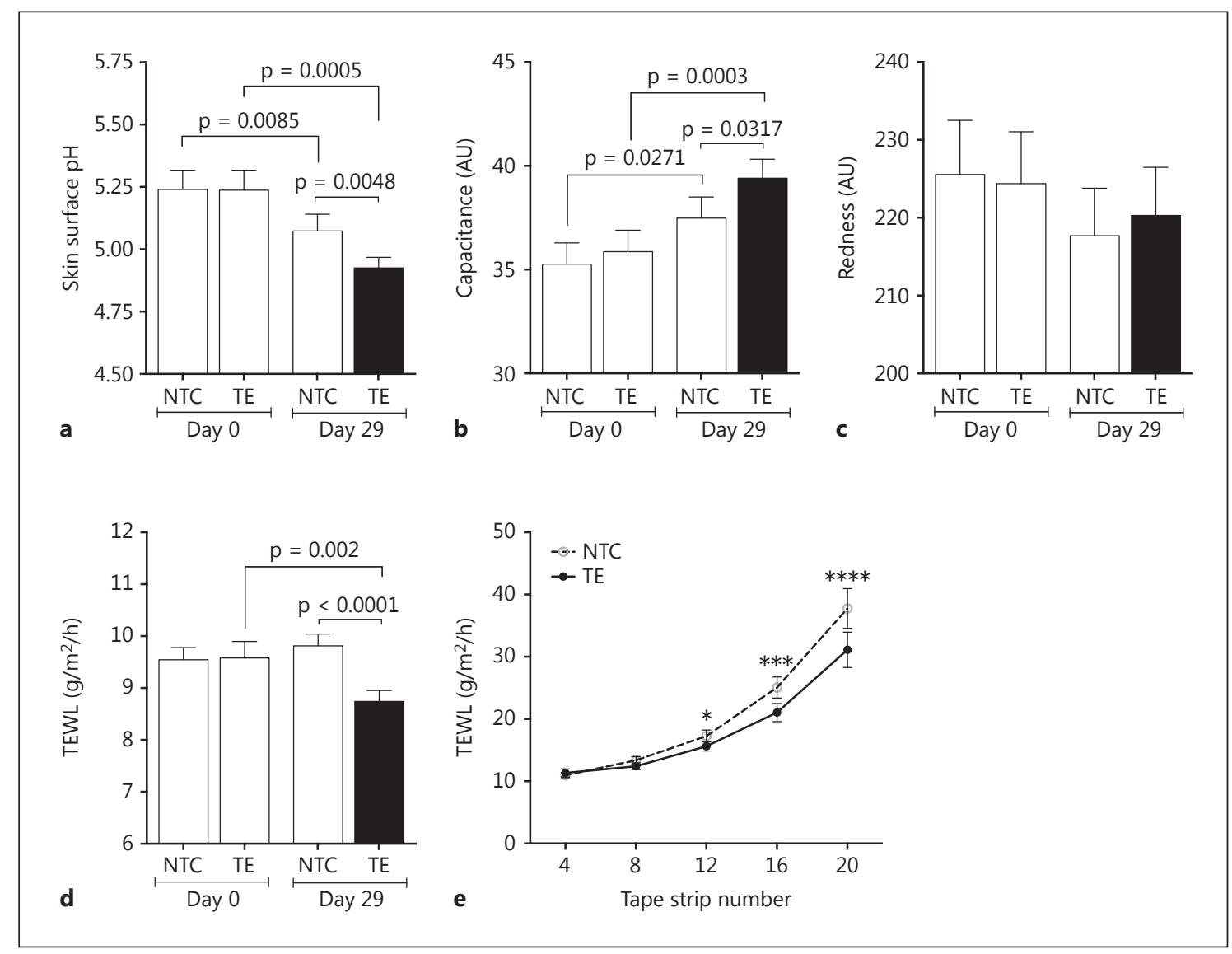

Fig. 1. The effect of 28-day treatment with the test emollient (TE), compared to an untreated control (NTC), on skin surface $\mathrm{pH}(\mathbf{a})$, hydration (b), redness (c), TEWL (d) and SC integrity (e) 12-20 h following the last application in people with dry skin over the age of $60(n=21)$. Two-way ANOVA reported a significant effect of test emollient treatment (and the interaction between treatment and tape strip number) on SC integrity. Asterisks indicate significant differences $(\mathrm{p}<0.05)$ reported using the Holm-Sidak posttest following a one-way ANOVA (a-d) and Bonferroni posttest with ${ }^{*} \mathrm{p}<0.05,{ }^{* * *} \mathrm{p}<0.001$, and ${ }^{* * * *} \mathrm{p}<0.0001$ (e). sive properties). The participants in cohort 3 treated 1 forearm with $1.28 \pm 0.126 \mathrm{~g}$ test emollient and the other forearm with 1.21 $\pm 0.120 \mathrm{~g}$ control emollient (randomized allocation) twice daily for 28 days. Before initiation and after cessation (12-20 h following the last application) of treatment, the biophysical properties of the test sites were assessed. Cohort 2 undertook a forearm-controlled study wherein a single application of test emollient (2 fingertip units) was made to 1 test site. Assessments were performed before and $3 \mathrm{~h}$ following treatment application.

\section{Biophysical Measurements}

Transepidermal water loss (TEWL) measurements were performed using an AquaFlux AF200 condensing chamber probe (Biox Systems Ltd., London, UK). Redness, capacitance and skin surface $\mathrm{pH}$ were measured using a Mexameter MX18, Corneometer CM825 and Skin pH Meter PH905, respectively (CK electronic $\mathrm{GmbH}$, Cologne, Germany). All assessments were performed in a room maintained at $21 \pm 2{ }^{\circ} \mathrm{C}$ and $38-50 \%$ relative humidity according to published guidelines [20]. All test sites were acclimatized to room conditions for $20 \mathrm{~min}$ before assessment.

The Effect of an Emollient on Skin Barrier Structure and Function
Tape-stripping, to experimentally disrupt the SC, was performed as previously described [21]. Prior to tape-stripping the test sites were cleaned with cotton wool and water, and allowed to reacclimatize for $20 \mathrm{~min}$. Extrapolation of depth reached by tape-stripping was based on the infrared absorbance (SquameScan 850A, CuDerm, Dallas, Tex., USA) of tape strips (to quantify protein) in accordance with published methodology $[22,23]$.

\section{SC Protease Activity}

Assessment of protease activity was made on samples comprising 3 consecutive tape strips as previously described [22]. Caseinolytic, chymotrypsin-like and trypsin-like activities were determined using EnzCheck ${ }^{\circledR}$ (Life Technologies Ltd., Paisley, UK), MeOSuc-Arg-Pro-Tyr-AMC (Peptide Protein Research Ltd., Funtley, UK), and Boc-Phe-Ser-Arg-AMC (Bachem, Bubendorf, Switzerland) substrates, respectively.

\section{Quantification of PCA and Lactate}

The levels of PCA in SC samples collected by tape-stripping (strips 4-6 pooled) were quantified as previously described [25]. 


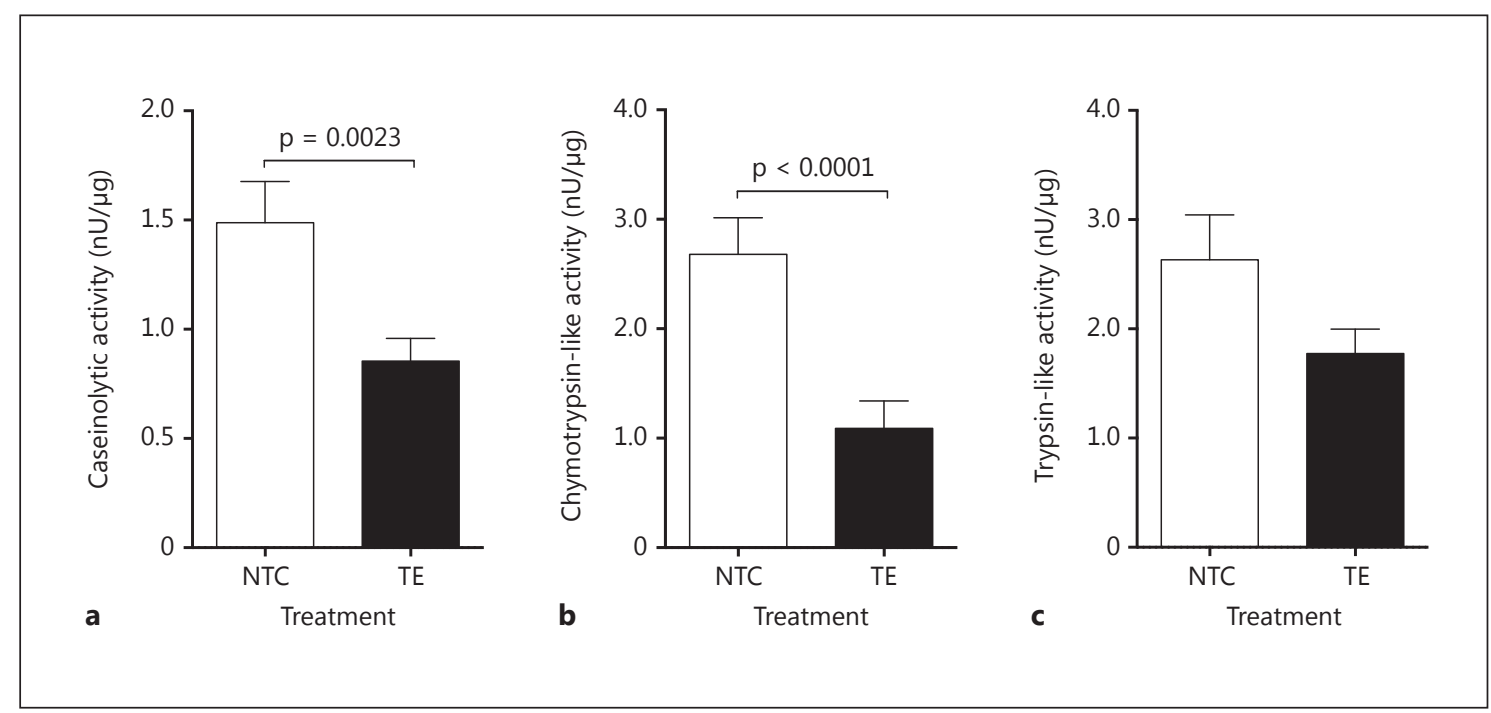

Fig. 2. The effect of 28-day treatment with the test emollient (TE) compared to an untreated control (NTC) on caseinolytic (a), chymotrypsin-like (b) and trypsin-like (c) protease activity. p values are the results of a paired t test.

Lactate samples were collected using a prewetted cotton swab, which was rubbed against the skin and then transferred to $1 \mathrm{ml}$ PBS. Lactate concentrations were determined using a fluorometric L-lactate assay (Abcam, Cambridge, UK) according to the manufacturer's instructions.

\section{Fourier Transform Infrared Spectroscopy}

Fourier transform infrared (FTIR) spectra were collected using a silver halide fibre-optic probe (FTIR Flexispec PIR 900, Art Photonics, Berlin, Germany) attached to a Nicolet iS50 FTIR spectrometer (Thermo Fisher Scientific Inc., Waltham, Mass., USA), equipped with a cooled mercury-cadmium-telluride detector and purged with dry $\mathrm{N}_{2}$. An average of 32 scans was collected for each measurement at a resolution of 4 wave numbers. Integration of peak intensities was performed using Omnic 9.0 software (Thermo Electron Corp., Madison, Wis., USA). Peak intensities in the spectral region from 4,000 to $2,000 \mathrm{~cm}^{-1}$ were normalized to the baseline at $3,800 \mathrm{~cm}^{-1}$, and intensities in the region from 2,000 to $1,000 \mathrm{~cm}^{-1}$ were normalized to the baseline at $1,850 \mathrm{~cm}^{-1}$ to account for contact pressure. The amount of water in the SC was determined by dividing the area of the peak at $3,300 \mathrm{~cm}^{-1}$, encompassing the vibrations from the $\mathrm{O}-\mathrm{H}$ of water and the $\mathrm{N}-\mathrm{H}$ of proteins, by the area of the peak at $1,550 \mathrm{~cm}^{-1}$, also relating to vibrations from $\mathrm{N}-\mathrm{H}$ bonds. Lipid chain conformation was determined as previously described [23]. Additional spectra were collected from solutions of lactic acid, citric acid, PCA, and urea in water, mineral oil (liquid paraffin), and ceramide (mixture from bovine brain) in chloroform (Sigma-Aldrich, UK). The contribution of water or chloroform was removed by spectral subtraction of a water-only control.

Data Analysis

The results were analysed by Prism v6.01 (Graphpad Software Inc., Calif., USA). The significance threshold was $\mathrm{p}<0.05$. Results are presented as means \pm standard error of the mean.

\section{Results}

\section{Effect of the Test Emollient on the Skin Barrier}

Treatment with the test emollient for 28 days significantly reduced TEWL and skin surface $\mathrm{pH}$ by an average of $1.07 \pm 0.29 \mathrm{~g} / \mathrm{m}^{2} / \mathrm{h}$ and $0.15 \pm 0.07 \mathrm{pH}$ units compared to the untreated control site, respectively, in volunteers with dry skin aged $>60$ years, suggesting a positive effect on underlying skin barrier function (fig. 1). Hydration was increased significantly $(+2.09 \pm 0.95$ units) compared to the untreated control despite the last application being $\geq 12 \mathrm{~h}$ previously. There was no effect of the treatment on skin redness, indicating that the test emollient is mild on aged skin under normal use conditions.

To further assess the effect of the test emollient on the integrity of the SC, tape-stripping to experimentally damage the SC in a controlled way was performed in conjunction with TEWL measurements (fig. 1e). TEWL consistently increased at a reduced rate on the site treated with the test emollient with each consecutive 4 tape strips compared to the untreated control suggesting a significantly increased SC integrity. The activity of extracellular proteases involved in desquamation is an important determinant of SC integrity. As such, we quantified broad-spectrum and peptide-specific activity in the superficial layers of the SC (fig. 2). Broad-spectrum activity was significantly reduced following treatment with the test emollient, as was chymotrypsin-like activity. Trypsin-like activity was also decreased, but not significantly. 


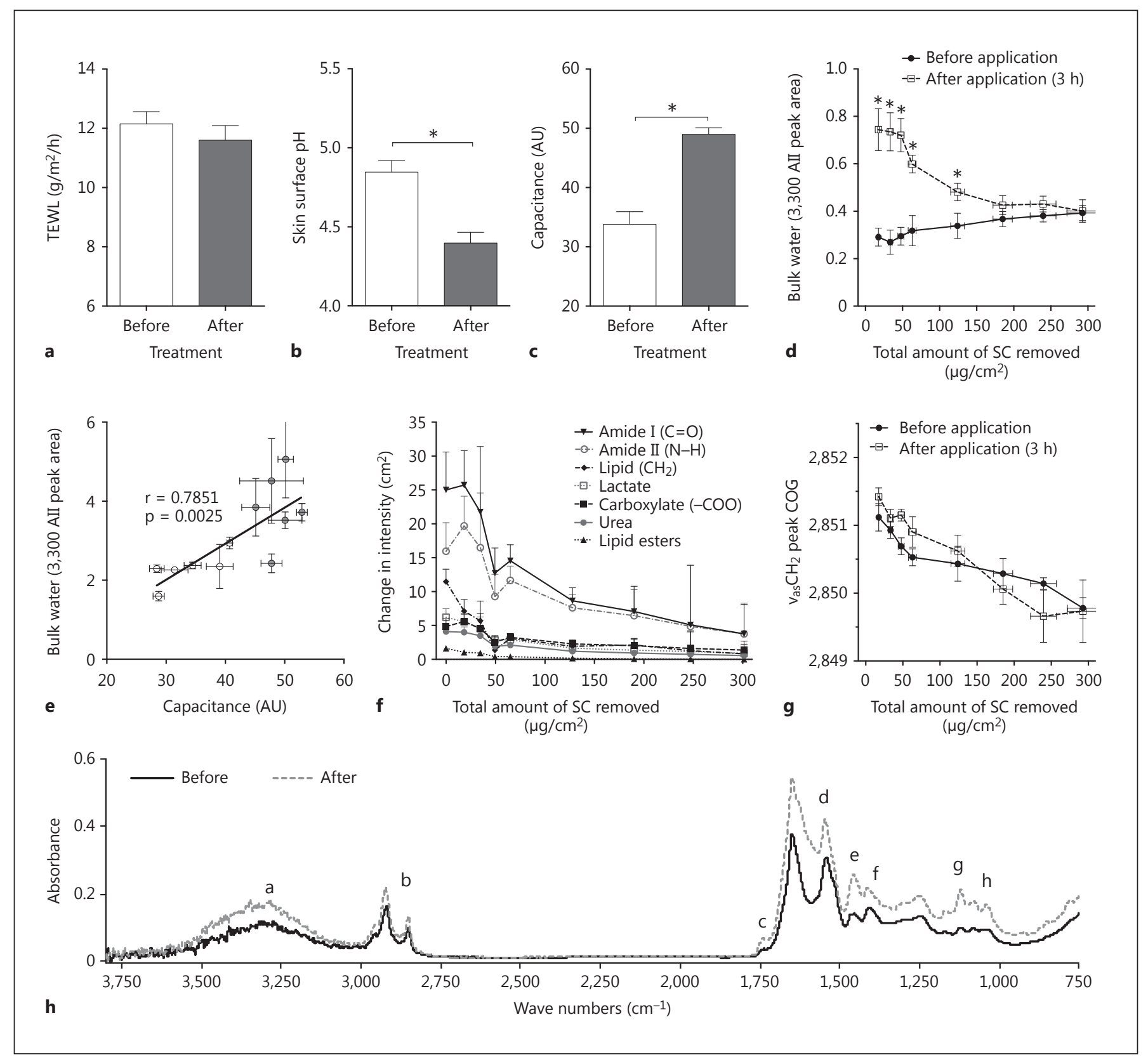

Fig. 3. The effect of a single application of the test emollient on the biophysical properties of the skin: TEWL (a), skin surface $\mathrm{pH}(\mathbf{b})$, and hydration (c) before and $3 \mathrm{~h}$ following application. $\mathbf{d}$ The concentration of water in the SC determined by FTIR spectroscopy before and $3 \mathrm{~h}$ following application. Measurements were collected in conjunction with tape-stripping to remove the uppermost layers of corneocytes and achieve greater depths. Two-way ANOVA reported a significant effect of test emollient treatment (and the interaction between treatment and tape strip number) on SC water content. AII $=$ Amide II. ${ }^{*} \mathrm{p}<0.05$. e Correlation between water concentration and capacitance (Pearson coefficient shown). Open circles correspond to measurements taken before treatment and filled circles to measurements taken after treatment. AII = Amide II. $\mathbf{f}$ The change in concentration of key functional groups
( $3 \mathrm{~h}$ posttreatment subtracted by pretreatment measurements) throughout the SC as determined by FTIR. $g$ The position of the peak at $2,850 \mathrm{~cm}^{-1}$, relating to the asymmetric stretching of $\mathrm{CH}_{2}$ lipid groups, throughout the depth of the SC. A two-way ANOVA reported no effect of treatment. $v_{\mathrm{as}}=$ Asymmetric stretching of the $\mathrm{CH}_{2}$ bond of lipids; $\mathrm{COG}=$ centre of gravity. $\mathbf{h}$ Example spectra collected before and after treatment. Regions identified on the spectra include: $\mathrm{a}=3,300 \mathrm{~cm}^{-1} \mathrm{O}-\mathrm{H}$ of water; $\mathrm{b}=2,920$ and 2,850 $\mathrm{cm}^{-1} \mathrm{CH}_{2}$ symmetric and asymmetric stretching of lipids; $\mathrm{c}=1,740$ $\mathrm{cm}^{-1}$ lipid esters; $\mathrm{d}=1,650$ and $1,550 \mathrm{~cm}^{-1}$ relating to amide I and amide II; e $=1,465 \mathrm{~cm}^{-1} \mathrm{CH}_{2}$ scissoring of lipids; $\mathrm{f}=1,410 \mathrm{~cm}^{-1}$ $\mathrm{COO}^{-}$carboxylates; $\mathrm{g}=1,175 \mathrm{~cm}^{-1} \mathrm{~N}-\mathrm{H}$ bending; $\mathrm{h}=1,124 \mathrm{~cm}^{-1}$ specific to lactate. 
The Short-Term Effects of the Test Emollient on SC Hydration

Having determined that 28 days of treatment with the test emollient exert positive effects on the underlying condition of the skin barrier, we next investigated the short-term emollient properties of the formulation. Three hours following a single application of the test emollient to the skin of adults $<50$ years of age with no skin complaints (cohort 2), TEWL decreased and SC capacitance increased indicative of skin occlusion (fig. 3a, c). Skin surface $\mathrm{pH}$ also decreased by $0.45 \pm 0.075$ units, and SC hydration increased by $15.17 \pm 2.40$ units on average (fig. $3 b$ ). Using FTIR, the molecular properties of the skin surface, to a depth of $1.5 \mu \mathrm{m}$, were determined before and after treatment. Tape-stripping was employed to achieve a greater depth profile, spanning approximately $4.5 \mu \mathrm{m} \mathrm{SC}$ depth in total (assuming an SC density of $100 \mu \mathrm{g} / \mu^{3} \mathrm{~m}^{3}$ ). Overall there were a number of changes to the spectra collected after treatment compared to before treatment, with the greatest changes observed at the skin surface (fig. $3 \mathrm{~h}$, without tape-stripping).

The amount of water in the SC, based on absorbance at $3,300 \mathrm{~cm}^{-1}$ (corresponding to $\mathrm{OH}$ bond of water) was elevated throughout most of this depth following treatment application (fig. 3d, significant to a depth of approx. $2.74 \mu \mathrm{m}$ based on measurement after removing $124.23 \pm$ $9.26 \mu \mathrm{m} \mathrm{SC}$ by tape-stripping). The mean intensity of the $3,300 \mathrm{~cm}^{-1}$ band across the depth of the SC directly correlated (Pearson's $r=0.785$ ) with capacitance measurements of SC hydration (fig. 3e, which measures across $10-20 \mu \mathrm{m}$ of the skin depth). Due to the reduced penetrative depth of FTIR compared to capacitance measurements, there is greater sensitivity for quantifying localized surface changes in water content using the former method.

Three hours following a single application of the test emollient, SC lipid levels were elevated, as indicated by the increased absorbance at 2,920 and $2,850 \mathrm{~cm}^{-1}$ corresponding to symmetric and asymmetric $\mathrm{CH}_{2}$ stretching of lipids. In the spectral region between 1,000 and 1,750 $\mathrm{cm}^{-1}$, there were further changes to the absorbance spectra of the skin that matched the spectra of the test emollient (online suppl. fig. 1a; for all online suppl. material, see www.karger.com/doi/10.1159/000445955). The absorbance spectrum of the test emollient is a composite of all its ingredients; the spectra of the major ingredients are presented in online supplementary figure $1 \mathrm{~b}$. The changes in absorbance (after vs. before treatment) at specific spectral regions highlighted in online supplementary figure 1 have been presented in figure $3 \mathrm{f}$. Absorbance is in- creased at regions centered on: $1,740 \mathrm{~cm}^{-1}$, corresponding to lipid esters such as those in sebum and natural oils; $1,650 \mathrm{~cm}^{-1}$, corresponding to the $\mathrm{C}=\mathrm{O}$ bond of proteins (amide I) for example; $1,540 \mathrm{~cm}^{-1}$, corresponding to the $\mathrm{N}-\mathrm{H}$ bond of proteins (amide II), ceramides and urea; $1,410 \mathrm{~cm}^{-1}$, corresponding to carboxylate groups (-COO); $1,175 \mathrm{~cm}^{-1}$, corresponding to urea, and 1,124 $\mathrm{cm}^{-1}$, corresponding to lactate. No significant difference in the chain conformation of SC lipids as a result of these compositional changes was observed (fig. 3g).

\section{Effect of the Test Emollient Compared to an Emollient} without Urea, Ceramide NP and Lactate on the Skin

Barrier

Having determined that the test emollient delivers moisturizing factors to the SC, and that this corresponds with increased water levels in the skin, we sought to directly compare its effect to an emollient without these added moisturizing factors, the control emollient (table 1). The effect of 28 days of treatment with the test emollient compared to the control emollient on the biophysical properties of the skin of volunteers aged over 60 years with self-reported dry skin is presented in figure 4 (cohort 3). There were no changes in skin redness indicating that neither formulation induces erythema under the conditions tested. Skin surface $\mathrm{pH}$ was significantly increased on the site treated with the control emollient compared to the test emollient $(+0.23 \pm 0.05$ units, $\mathrm{p}=$ $0.0007)$ and compared to the baseline measurements $(+0.30 \pm 0.07$ units, $\mathrm{p}=0.0015)$. TEWL was unchanged following treatment with the test emollient $(11.27 \pm 0.19$ $\mathrm{g} / \mathrm{m}^{2} / \mathrm{h}$ before and $11.58 \pm 0.23 \mathrm{~g} / \mathrm{m}^{2} / \mathrm{h}$ after). Following treatment with the control emollient, TEWL increased from $11.15 \pm 0.23$ to $11.94 \pm 0.26 \mathrm{~g} / \mathrm{m}^{2} / \mathrm{h}(\mathrm{p}<0.01)$ suggesting a small reduction in skin barrier function. Moreover, the integrity of the SC was significantly decreased at the site treated with the control emollient, indicated by elevated TEWL throughout tape-stripping (fig. 4e), when compared to both pretreatment assessments of the test area (adjacent test site) and the sites treated with the test emollient at the same time point.

Because the emollients differentially affected SC integrity and skin surface $\mathrm{pH}$, assessment of SC proteolytic activity was also performed (fig. 5). In line with cohort 1 , the test emollient reduced broad-spectrum activity by $0.36 \pm$ $0.16 \mathrm{nU} / \mu \mathrm{g}$ compared to the control emollient, which exhibited similar activity compared to the untreated sites in cohort 1 (fig. 2a). There was no difference in chymotrypsin-like activity between the test and control emollienttreated sites, suggesting that both treatments inhibit this 

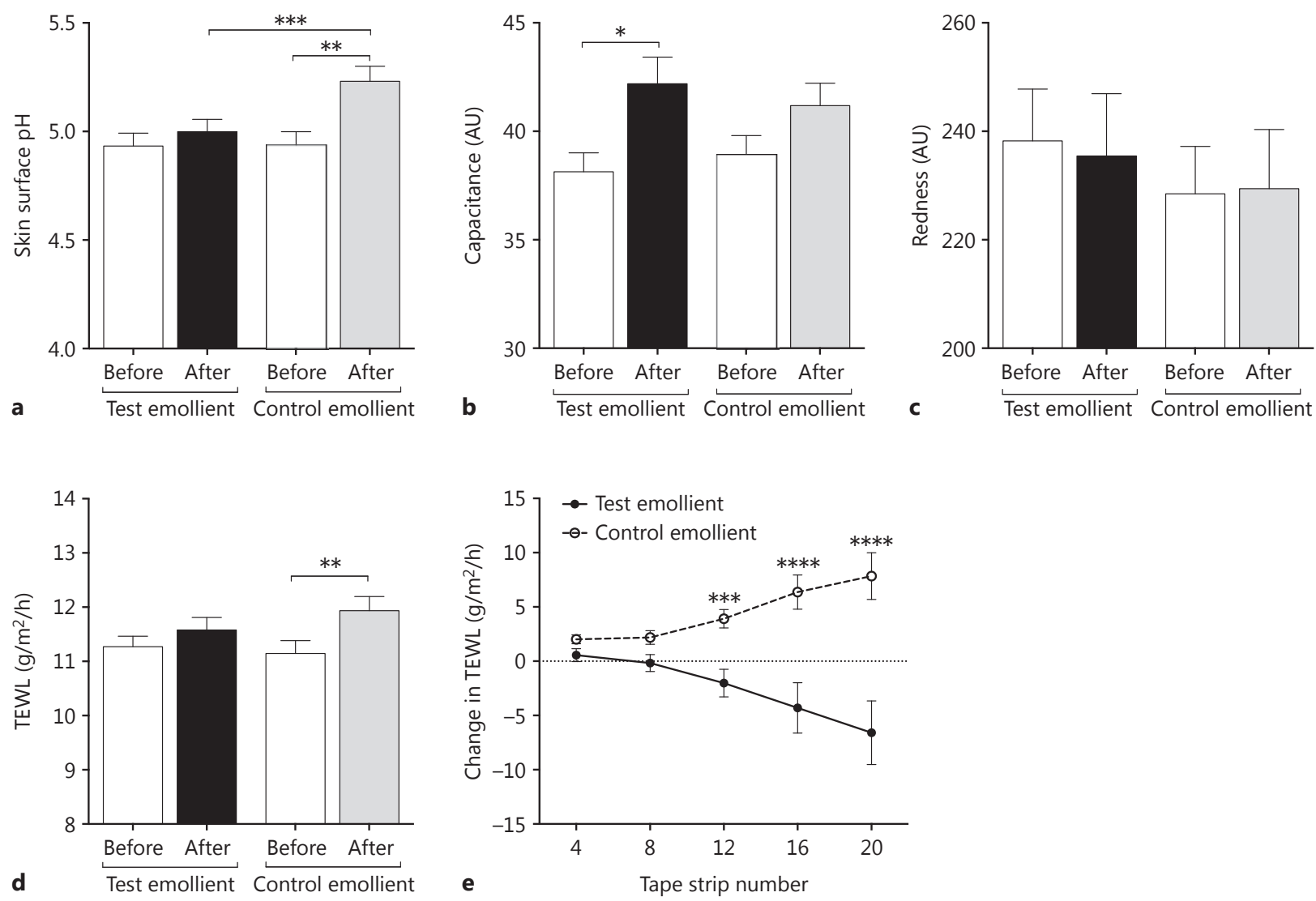

Fig. 4. The effect of 28-day treatment with the test emollient, compared to the control emollient on skin surface $\mathrm{pH}(\mathbf{a})$, hydration (b), redness (c), skin barrier function (d) and SC integrity (e) 12 $20 \mathrm{~h}$ following the last application in people with dry skin over the age of $60(n=18)$. For $\mathbf{a}-\mathbf{d}$, a one-way ANOVA found significant differences between the groups for TEWL ( $p=0.0018)$, hydration $(\mathrm{p}=0.0026)$ and skin surface $\mathrm{pH}(\mathrm{p}=0.0002)$. Asterisks indicate

activity (see also fig. 2b). Trypsin-like activity was significantly increased by $1.20 \pm 0.59 \mathrm{nU} / \mu \mathrm{g}$ on the sites treated with the control compared to the test emollient, which exhibited similar activity to untreated skin (fig. 2c). Elevated proteolytic activity is therefore a potential mechanism by which SC integrity is reduced following treatment with the control emollient.

Skin hydration increased by $12.2 \pm 5.40 \%$ following treatment with the test emollient and $6.6 \pm 3.51 \%$ following treatment with the control (12-20 $\mathrm{h}$ following last application); however, the increase was only significant for the test emollient (fig. 4). To better understand how the emollients alter hydration, levels of two NMF components the results of a Bonferroni posttest: ${ }^{*} \mathrm{p}<0.05,{ }^{* *} \mathrm{p}<0.01,{ }^{* * *} \mathrm{p}<$ 0.001 . e SC integrity is displayed as the change from baseline $\left(T E W L_{\text {after }}-T-W L_{\text {before}}\right)$. A two-way ANOVA reported a significant difference between the test and control emollient-treated sites. Asterisks indicate the results of a Bonferroni posttest: ${ }^{* * *} \mathrm{p}<$ $0.001,{ }^{* * * *} \mathrm{p}<0.0001$.

in the SC were quantified (fig. 6). Lactate is readily detectable in superficial skin samples and was used as a marker for the delivery of exogenous moisturizing factors from the test emollient. PCA, not present in either of the formulations tested, is a useful biomarker for total filaggrinderived NMF components and was employed to determine the effect of the treatments on endogenous moisturizing factor levels [24]. Lactate was significantly elevated (by $57 \%$ on average) in the SC of test emollient- but not control emollient-treated skin $>12 \mathrm{~h}$ following the last application. The amount of lactate in the skin was also found to significantly correlate with skin surface $\mathrm{pH}$, helping explain the difference in skin surface $\mathrm{pH}$ between the sites 


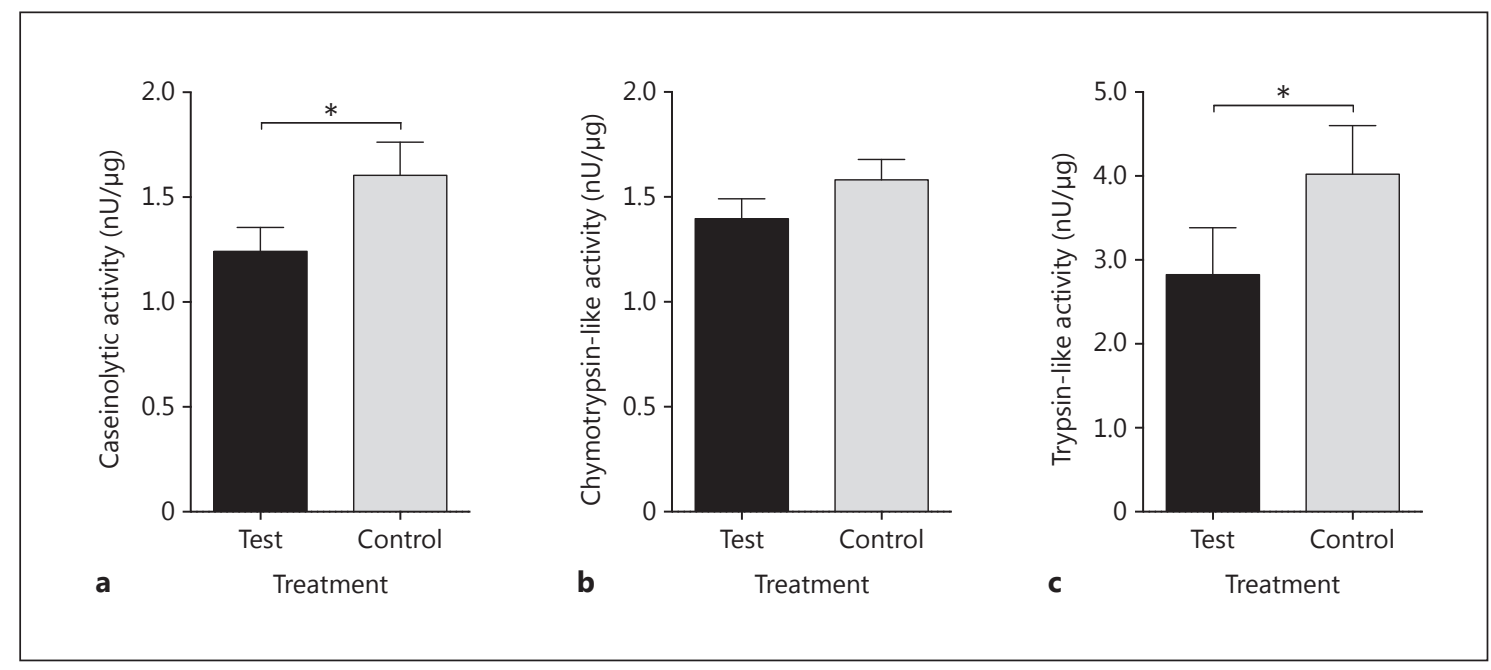

Fig. 5. The effect of 28-day treatment with the test emollient compared to the control emollient on caseinolytic (a), chymotrypsin-like (b) and trypsin-like (c) protease activity. Asterisks indicate the results of a paired test: $* \mathrm{p}<0.05$.

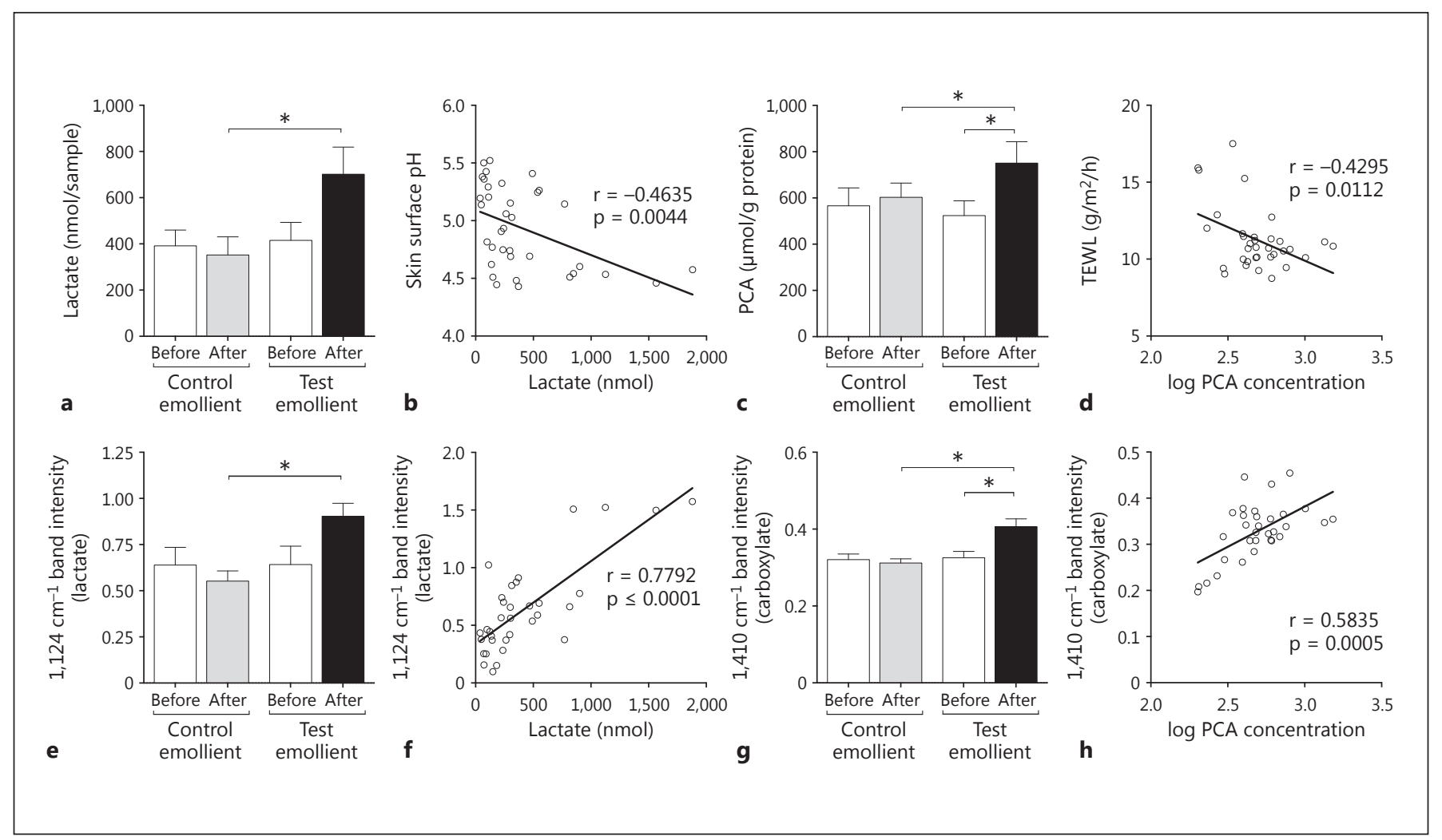

Fig. 6. The effect of 28-day treatment with the test emollient compared to the control emollient on lactate levels quantified from skin swabs (a), PCA levels quantified from tape strip samples (c), FTIRdetermined lactate levels based on absorbance at $1,124 \mathrm{~cm}^{-1}(\mathbf{e})$, and FTIR-determined carboxylic acid levels based on absorbance at $1,410 \mathrm{~cm}^{-1} /$ amide II (g) $12-20 \mathrm{~h}$ following the last application in people with dry skin over the age of $60(n=18)$. A one-way ANOVA found significant differences between the groups for lactate $(\mathrm{p}=$ $0.0154)$, PCA ( $\mathrm{p}=0.0002), 1,124 \mathrm{~cm}^{-1}(\mathrm{p}=0.0275)$, and 1,410 $\mathrm{cm}^{-1} /$ amide II $(\mathrm{p} \leq 0.0001)$. Asterisks indicate the results of a Bonferroni posttest: ${ }^{*} \mathrm{p}<0.05$. Correlations between the parameters and biophysical measurements are presented in $\mathbf{b}, \mathbf{d}, \mathbf{f}$, and $\mathbf{h}$. 
Fig. 7. Correlation between FTIR-determined carboxylic acids in the SC and measures of hydration, including capacitance (a) and FTIR-determined water content (b). Open circles represent measurement taken before treatment, grey circles that following treatment with the control emollient and black circles that following treatment with the test emollient. Dashed lines represent the linear relationship between the parameters for all groups and the solid line the one for the test emollient-treated group only.

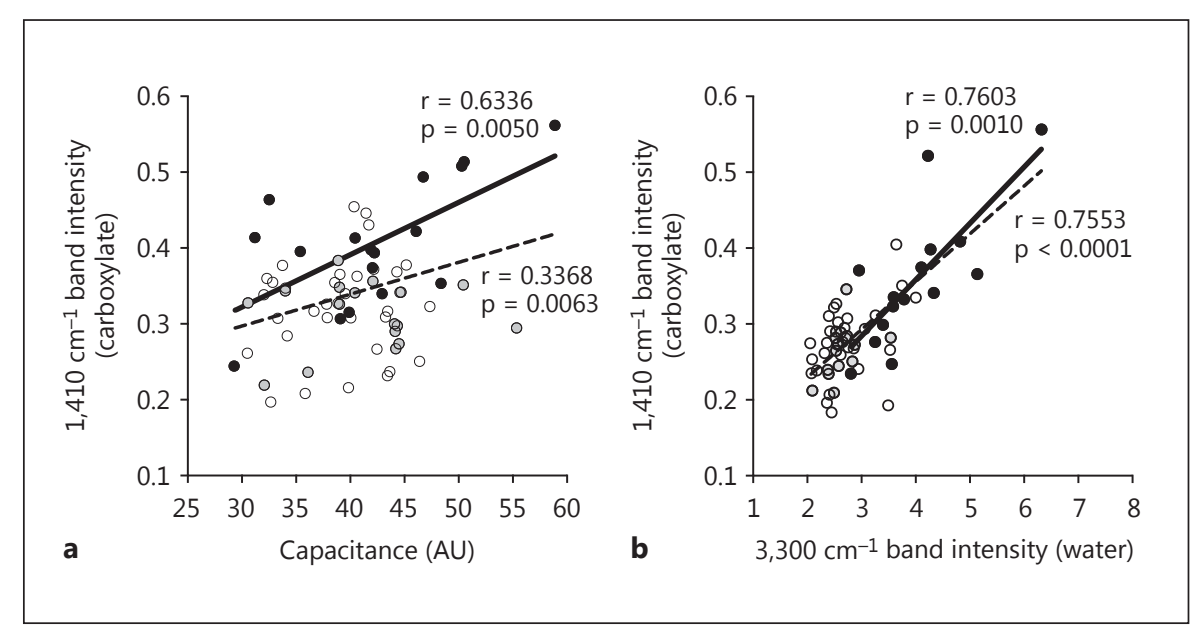

treated with the test and control emollients (fig. 6b). Interestingly PCA was also significantly elevated (by 43\%) following treatment with the test emollient but not the control emollient, suggesting that treatment with the test emollient promotes endogenous NMF production (PCA not present in either topical formulation). The levels of PCA were correlated with skin barrier function (fig. 6d).

FTIR spectroscopy was conducted at the skin surface and following 3 consecutive tape strips to determine the molecular properties of the skin to a depth of $0-1.5 \mu \mathrm{m}$ and to a depth of $0.56-2.06 \mu \mathrm{m}$, respectively (based on the removal of $55.71 \pm 2.35 \mu \mathrm{m}$ protein by tape-stripping - no difference between the protein removed from the test sites was found using a one-way ANOVA). Example absorbance spectra of the skin before and after treatment are presented in online supplementary figure 2 , and the mean changes in the spectral features identified are detailed in online supplementary table 1 . The amount of water in the skin increased significantly on the sites treated with the test emollient but remained unchanged on the sites treated with control emollient. The amount of lipid $\left(\mathrm{vCH}_{2}\right.$ and $\delta \mathrm{CH}_{2}$ ) groups on and within the skin increased significantly on both the test and control emollient-treated sites. In contrast, the intensity of the peaks at $1,740 \mathrm{~cm}^{-1}$ (lipid esters), 1,650 $\mathrm{cm}^{-1}$ (amide I), 1,550 $\mathrm{cm}^{-1}$ (amide II), 1,410 $\mathrm{cm}^{-1}$ (carboxyl group), $1,175 \mathrm{~cm}^{-1}$ (urea), and $1,124 \mathrm{~cm}^{-1}$ (lactate) are all significantly higher on the sites treated with the test emollient compared to the control emollient. Each of the peaks relates to specific molecular bonds, as opposed to specific compounds, so it is not possible to determine the changes in specific skin components. The intensity of the peak at $1,124 \mathrm{~cm}^{-1}$, relating to lactate, did correlate with lactate levels quantified from the skin sam-

The Effect of an Emollient on Skin Barrier Structure and Function ples (fig. $6 \mathrm{e}, \mathrm{f}$ ). The peak at $1,410 \mathrm{~cm}^{-1}$ corresponding to the carboxyl group of skin humectants, including PCA, is also contributed to by ceramides and urea. When normalized to the amide II peak, to enrich for carboxylic acids (i.e. to remove the contribution of molecules containing the $\mathrm{N}-\mathrm{H}$ group such as ceramides and urea), the intensity of the peak at $1,410 \mathrm{~cm}^{-1}$ correlates well with PCA levels quantified in the skin (fig. 6h). In agreement with HPLC-derived PCA levels, a significant increase in carboxylic acids was indicated by the change in the 1,410 $\mathrm{cm}^{-1}$ /amide II ratio following treatment with the test emollient (fig. 6g). Increases in ceramide, urea and/or protein levels following treatment with the test emollient are also suggested by the increase in amide I and 1,175 $\mathrm{cm}^{-1}$ peak intensities. Notably treatment with the control emollient actually reduced the levels of amide bonds within the SC, most likely because the ceramide, urea and/or protein fraction of the SC had been displaced by the increase in lipids.

To determine whether changes in carboxylic acid and ceramide/urea/protein levels affect skin hydration, they were correlated with capacitance measurements (fig. 7). The $1,410 \mathrm{~cm}^{-1} /$ amide II ratio correlated weakly with capacitance and strongly with FTIR-determined SC water content. The lower correlation with capacitance can be linked to the different penetration depths of the techniques. Following treatment with the test emollient, where changes in water and carboxylic acid levels occur predominantly in the uppermost layers of the SC from where FTIR measurements are gathered, the correlation with capacitance improved. A significant correlation between amide II peak intensities and capacitance or FTIR SC water content was not observed. 


\section{Discussion}

The finding that aqueous cream BP damages the skin barrier highlighted the need to better understand the effect of emollients on the skin $[15,18]$. In contrast to aqueous cream, the test emollient, after 28 days of treatment, improved skin barrier function (decreased TEWL) and SC integrity compared to an untreated control in volunteers with dry skin aged over 60 years. The negative effects of aqueous cream have been attributed to the use of SLS as an emulsifier [17, 25]. SLS is a standard skin irritant, eliciting multiple negative effects on the skin including elevation of skin surface $\mathrm{pH}$ and reduction in skin barrier function (elevated TEWL) [26]. The use of relatively (relative to SLS) milder non-ionic surfactants with reduced irritant potential likely contributes to the improved effect of the test emollient [27]. These same beneficial effects were not observed when the control emollient, also formulated with milder (relative to SLS) surfactants, was used to treat dry skin for 28 days. Whilst not as damaging as aqueous cream, the control emollient was associated with elevated TEWL and reduced SC integrity. The response of participants with a history of $\mathrm{AD}(33 \%)$ was different to those without a history of $\mathrm{AD}$; however, the size of the subgroups was not large enough to permit a proper subgroup analysis. Nevertheless, evidence already shows that individuals with a history of $\mathrm{AD}$ are more prone to skin barrier damage from topical products $[15,17]$. Neither treatment adversely affected lipid chain conformation determined by FTIR [23]; however, the control emollient was associated with significantly elevated skin surface $\mathrm{pH}$ and protease activity compared to the test emollient. A pH-induced elevation of protease activity is an established mechanism of skin barrier breakdown, characterized by degradation of corneodesmosomal junctions in the SC [28]. The differential effect of the treatments on $\mathrm{SC} \mathrm{pH}$ and protease activity may therefore explain the different effects of the treatments on skin barrier function and SC integrity.

Whilst the surfactant/emulsification system employed could account for the elevation of skin surface $\mathrm{pH}$ following treatment with the control emollient, it is unlikely to account for the reduction in skin surface $\mathrm{pH}$ brought about by the test emollient. The long-term reduction of skin surface $\mathrm{pH}$ using topical treatments has recently been found to improve both skin barrier function and hydration, in agreement with the results presented here [29]. Skin surface $\mathrm{pH}$ is regulated via several mechanisms, e.g. by the generation of acidic natural moisturizing factors such as urocanic acid and lactic acid $[30,31]$. The skin surface $\mathrm{pH}$ of the subjects recruited in this study dis- played a significant direct relationship with the level of lactate in the skin. Moreover treatment with the test emollient, unlike with the control emollient, elevated lactate levels in the skin for more than $24 \mathrm{~h}$ following the last application. Aged skin contains significantly reduced levels of some carboxylates, including lactate and PCA, which may account for the elevated skin surface $\mathrm{pH}$ and propensity for xerosis $[5,32,33]$. It is interesting therefore that the test emollient maintains skin surface $\mathrm{pH}$ by replenishing the carboxylate pool.

The greatest difference between the emollients tested was their effect on hydration. While the control emollient was poorly hydrating, the test emollient imparted clinically relevant levels of elevated hydration (similar in scale to the difference in hydration between healthy and $\mathrm{AD}$ skin $[34,35])$ for more than $24 \mathrm{~h}$ after cessation of treatment. The increase in hydration outlasted the transient occlusive effect of the cream and can therefore be attributed to an increased ability of the SC to hold onto moisture. Humectants, including urea and lactate found in the test emollient, are naturally present in the SC and contribute to its water-holding capacity [5]. Ceramide, also present in the test cream, is a component of the lipid matrix that contributes to SC permeability barrier function [36]. Emollients containing ceramide NP have been shown to both hydrate the skin and improve TEWL [37]. Following treatment with the test but not the control emollient, significant increases in the levels of humectants and natural skin lipids were observed by FTIR spectroscopy. Using this technique it was not possible to distinguish between specific compounds; however, the SC pool of carboxylic acids and the combined levels of urea, ceramides, and protein increased significantly following a single application of the test emollient and remained elevated for at least $24 \mathrm{~h}$ after a 28 -day treatment regimen. The carboxylate pool in particular was significantly correlated with the increased water-holding capacity of the skin. Urea is the predominant humectant in the test emollient and so also likely accounts for a significant proportion of the SC's improved water-holding capacity [38]. The hydrating effect of urea has been demonstrated in a range of bases previously (reviewed in Pan et al. [39] and Loden [40]).

While humectants like urea and lactate have very positive effects on the skin, excessive hydration caused by excessive humectant levels can lead to enhanced proteolytic degradation of the SC $[41,42]$, indicating that the correct humectant concentration is crucial to barrier repair. We observed no reduction in SC integrity in conjunction with decreased protease activity, indicating that an appropriate urea concentration was used to balance 
positive and negative effects in this study population. The combination with lactic acid maintaining skin surface $\mathrm{pH}$ may contribute to the overall positive effect observed in this regard [43].

In addition to imparting skin moisturization, urea has recently been shown to significantly improve skin barrier function in healthy volunteers when applied once daily for 4 weeks in a $20 \%$ cream preparation [44]. This improvement was associated with the elevated expression of genes involved in SC homeostasis, including the FLG gene encoding filaggrin. A $10 \%$ urea preparation increased FLG expression to the same extent. Concentrations less than $10 \%$ were not tested in this particular study; however, formulations containing 5\% urea have been shown to strengthen the skin barrier in a series of other studies $[45,46]$. Moreover the barrier-strengthening properties of the emollients were linked to the ability of the emollients to delay relapses of both AD and hand eczema in young adults $[13,47-49]$. The results of this study further demonstrate that a distinct 5\% urea preparation with ceramide NP and lactate also imparts positive effects on skin barrier function and SC integrity in an older population. In addition, a significant rise in PCA levels, a product of filaggrin catabolism, in the SC following treatment with the test emollient (which does not contain PCA) but not the control emollient was observed. PCA levels tend to coincide with urocanic acid and free amino acid levels, because they are all derived from filaggrin breakdown [24]. TEWL was also found to correlate with PCA levels in this study, in line with the relationship between filaggrin levels and TEWL. Given that PCA is not an ingredient of the emollients tested, this finding supports the ability of topical urea preparations to induce filaggrin gene expression, when formulated into a prescription emollient at $5 \%$. Moreover, it demonstrates that this increase in expression leads to increased filaggrin levels and subsequently increased NMF levels. This new finding further reinforces the potential barrier-strengthening properties of emollient creams. In addition the level of lactate, a non-filaggrin-derived NMF component, was also specifically increased following treatment with the test emollient. Lactate elicits biological effects on the skin, resulting in enhancement of lipid synthesis, and as such may contribute to the positive effects of the test emollient on skin barrier homeostasis [50].

The test emollient also contains ceramide NP, a component of the lipid lamellae. Ceramides, the levels of which decrease with advancing age, are essential for optimum lipid structure and permeability barrier function $[3,23,51]$. In this study we were unable to specifically

The Effect of an Emollient on Skin Barrier Structure and Function show whether ceramide NP was taken up by the skin due to the overlapping spectral profiles of ceramides, urea and protein. Lipid esters were elevated following treatment with the test emollient; however, their penetration was limited. Sebum is a source of triglycerides (lipid esters) on the skin surface, and its production was found to decline in women with advancing age [52]. The level of total lipids, which includes non-physiological lipids (of white soft paraffin and liquid paraffin), increases significantly following treatment with both topical emollients. The combination of lipid changes following treatment with the test emollient did not appear to affect lipid chain conformation; however, it remains possible that the physiological lipids, such as ceramide NP, contributed to the decrease in TEWL and improvement in SC integrity found following treatment with the test emollient $[37,50]$. With respect to SC hydration, the relative proportion of moisturizing factors to lipids was important, wherein the size of the carboxylate pool was linked to SC water content.

Taken together, the added humectants (lactate and urea) and the increased levels of endogenously produced humectants (PCA) are important in imparting the significant increase in skin hydration following treatment with the test emollient and for the reduction of skin surface $\mathrm{pH}$ and improvement in the structure and function of the skin barrier. Importantly the levels of these metabolites are depleted in aged and xerotic skin, and correlate with the severity of xerotic skin conditions such as $\mathrm{AD}[5$, $24,53,54]$. Low NMF levels associated with an FLG gene mutation are a major risk factor for the development of $\mathrm{AD}$, and by extension also asteatotic eczema $[1,55,56]$. The test emollient therefore addresses an important pathological process in xerotic skin conditions, setting it apart from emollients without humectants and skin lipids like the control emollient tested here.

In conclusion, the test emollient (containing 5\% urea, ceramide NP and lactate) significantly hydrated the skin to a greater extent, and for a longer period of time, compared to an emollient containing no skin-moisturizing factors, and imparted additional benefits to the structure and function of the skin barrier. As such there is a convincing rationale for differentiating emollients based on their composition of SC constituents [19]. In this case the test emollient was well tolerated in people with dry skin aged over 60 years and addressed the pathological features of dry skin, supporting a role for this class of emollient as a first-line treatment for xerotic skin conditions in the aged population. The structural/biophysical and biological (enhanced FLG expression) effects of urea and lactate in the test emollient, and combination of natural skin lip- 
ids, mean that generalizability with other humectant emollients is tenuous [57]. As such an evidence-based approach is always recommended for selecting emollients, as not all emollient cream formulations are the same.

\section{Statement of Ethics}

Written informed consent was obtained from all participants and a record kept in the study site file. The NHS Trent Research Ethics Committee approved the study, including the consent procedure employed (No. 04/MREC/70).

\section{Disclosure Statement}

We are grateful to all our volunteers who have given up their time to take part in our studies. Thanks also go to Les Hunter for the recruitment of volunteers who participated in this study and Jon Kilby and Rob Hanson for their technical assistance.

This study was supported by research funding from Almirall SA, Barcelona.
M.J.C. and S.G.D. have received fees for giving lectures for Almirall SA. and attending advisory boards. M.J.C. and S.G.D. have received funding for investigator-led research from Almirall, Astellas, Bayer, MSD, and Stiefel-GSK, all of whom are manufacturers of emollients.

\section{References}

1 Paul C, Maumus-Robert S, MazereeuwHautier J, Guyen CN, Saudez X, Schmitt AM: Prevalence and risk factors for xerosis in the elderly: a cross-sectional epidemiological study in primary care. Dermatology 2011;223: 260-265.

2 Jin K, Higaki Y, Takagi Y, Higuchi K, Yada Y, Kawashima M, Imokawa G: Analysis of betaglucocerebrosidase and ceramidase activities in atopic and aged dry skin. Acta Derm Venereol 1994;74:337-340.

3 Rogers J, Harding C, Mayo A, Banks J, Rawlings A: Stratum corneum lipids: the effect of ageing and the seasons. Arch Dermatol Res 1996;288:765-770.

4 Ghadially R, Brown BE, Sequeira-Martin SM, Feingold KR, Elias PM: The aged epidermal permeability barrier. Structural, functional, and lipid biochemical abnormalities in humans and a senescent murine model. J Clin Invest 1995;95:2281-2290.

5 Harding CR, Watkinson A, Rawlings AV, Scott IR: Dry skin, moisturization and corneodesmolysis. Int J Cosmet Sci 2000;22:2152.

6 Wilhelm KP, Brandt M, Maibach H: Transepidermal water loss and barrier function of aging human skin; in Fluhr J (ed): Bioengineering of the Skin: Water and Stratum Corneum. Boca Raton, CRC Press, 2006, pp 143158.

7 Cork MJ, Danby S: Skin barrier breakdown: a renaissance in emollient therapy. Br J Nurs 2009; 18:872, 874, 876-877.

8 Cork MJ, Danby SG, Vasilopoulos Y, Hadgraft J, Lane ME, Moustafa M, Guy RH, Macgowan AL, Tazi-Ahnini R, Ward SJ: Epidermal barrier dysfunction in atopic dermatitis. J Invest Dermatol 2009;129:1892-1908.

9 Buraczewska I, Berne B, Lindberg M, Torma $\mathrm{H}$, Loden $\mathrm{M}$ : Changes in skin barrier function following long-term treatment with moistur- izers, a randomized controlled trial. Br J Dermatol 2007;156:492-498.

10 Held E, Lund H, Agner T: Effect of different moisturizers on SLS-irritated human skin. Contact Dermatitis 2001;44:229-234.

11 Chamlin SL, Kao J, Frieden IJ, Sheu MY, Fowler AJ, Fluhr JW, Williams ML, Elias PM: Ceramide-dominant barrier repair lipids alleviate childhood atopic dermatitis: changes in barrier function provide a sensitive indicator of disease activity. J Am Acad Dermatol 2002;47:198-208.

12 Msika P, De Belilovsky C, Piccardi N, Chebassier N, Baudouin C, Chadoutaud B: New emollient with topical corticosteroid-sparing effect in treatment of childhood atopic dermatitis: SCORAD and quality of life improvement. Pediatr Dermatol 2008;25:606-612.

13 Wiren K, Nohlgard C, Nyberg F, Holm L, Svensson M, Johannesson A, Wallberg P, Berne B, Edlund F, Loden M: Treatment with a barrier-strengthening moisturizing cream delays relapse of atopic dermatitis: a prospective and randomized controlled clinical trial. J Eur Acad Dermatol Venereol 2009;23:12671272 .

14 Al Enezi T, Sultan A, Chittock J, Moustafa M, Danby S, Cork MJ: Breakdown of the skin barrier induced by aqueous cream: implications for the management of atopic eczema. 89th Annual Meeting of the British Association of Dermatologists, Glasgow, 2009.

15 Danby S, Al Enezi T, Sultan A, Chittock J, Kennedy K, Cork MJ: The effect of aqueous cream BP on the skin barrier in volunteers with a previous history of atopic dermatitis. Br J Dermatol 2011;165:329-334.

16 Mohammed D, Matts PJ, Hadgraft J, Lane ME: Influence of aqueous cream on corneocyte size, maturity, skin protease activity, protein content and trans-epidermal water loss. Br J Dermatol 2011;164:1304-1310.
17 Tsang M, Guy RH: Effect of aqueous cream $\mathrm{BP}$ on human stratum corneum in vivo. $\mathrm{Br}$ Dermatol 2010;163:954-958.

18 Cork MJ, Timmins J, Holden C, Carr J, Berry V, Ward SJ, Tazi-Ahnini R: An audit of adverse drug reactions to aqueous cream in children with atopic eczema. Pharm J 2003;271: 746-747.

19 Moncrieff G, Cork M, Lawton S, Kokiet S, Daly C, Clark C: Use of emollients in dry-skin conditions: consensus statement. Clin Exp Dermatol 2013;38:231-238; quiz 238.

20 Pinnagoda J, Tupker RA, Agner T, Serup J: Guidelines for transepidermal water loss (TEWL) measurement. A report from the standardization group of the European Society of Contact Dermatitis. Contact Dermatitis 1990;22:164-178.

21 Danby SG, Chittock J, Brown K, Albenali LH, Cork MJ: The effect of tacrolimus compared to betamethasone valerate on the skin barrier in volunteers with quiescent atopic dermatitis. Br J Dermatol 2014;170:914-921.

22 Voegeli R, Rawlings AV, Doppler S, Heiland J, Schreier T: Profiling of serine protease activities in human stratum corneum and detection of a stratum corneum tryptase-like enzyme. Int J Cosmet Sci 2007;29:191-200.

23 Damien F, Boncheva M: The extent of orthorhombic lipid phases in the stratum corneum determines the barrier efficiency of human skin in vivo. J Invest Dermatol 2010;130:611614

24 Kezic S, O’Regan GM, Yau N, Sandilands A, Chen H, Campbell LE, Kroboth K, Watson R, Rowland M, McLean WH, Irvine AD: Levels of filaggrin degradation products are influenced by both filaggrin genotype and atopic dermatitis severity. Allergy 2011;66:934-940.

25 Cal K: Unwelcome skin penetration enhancers: a fly in the ointment. J Cosmet Dermatol 2009;8:144-145. 
26 Tupker RA, Willis C, Berardesca E, Lee CH, Fartasch M, Agner T, Serup J: Guidelines on sodium lauryl sulfate (SLS) exposure tests. A report from the standardization group of the European Society of Contact Dermatitis. Contact Dermatitis 1997;37:53-69.

27 Ananthapadmanabhan KP, Moore DJ, Subramanyan K, Misra M, Meyer F: Cleansing without compromise: the impact of cleansers on the skin barrier and the technology of mild cleansing. Dermatol Ther 2004;17(suppl 1):16-25.

28 Hachem JP, Man MQ, Crumrine D, Uchida Y, Brown BE, Rogiers V, Roseeuw D, Feingold KR, Elias PM: Sustained serine proteases activity by prolonged increase in $\mathrm{pH}$ leads to degradation of lipid processing enzymes and profound alterations of barrier function and stratum corneum integrity. J Invest Dermatol 2005; 125:510-520.

29 Blaak J, Kaup O, Hoppe W, Baron-Ruppert G, Langheim H, Staib P, Wohlfart R, Luttje D, Schurer N: A long-term study to evaluate acidic skin care treatment in nursing home residents: impact on epidermal barrier function and microflora in aged skin. Skin Pharmacol Physiol 2015;28:269-279.

30 Rippke F, Schreiner V, Doering T, Maibach HI: Stratum corneum $\mathrm{pH}$ in atopic dermatitis: impact on skin barrier function and colonization with Staphylococcus aureus. Am J Clin Dermatol 2004;5:217-223.

31 Winge MC, Hoppe T, Berne B, Vahlquist A, Nordenskjold M, Bradley M, Torma H: Filaggrin genotype determines functional and molecular alterations in skin of patients with atopic dermatitis and ichthyosis vulgaris. PLoS One 2011;6:e28254.

32 Egawa M, Tagami H: Comparison of the depth profiles of water and water-binding substances in the stratum corneum determined in vivo by Raman spectroscopy between the cheek and volar forearm skin: effects of age, seasonal changes and artificial forced hydration. Br J Dermatol 2008; 158 : 251-260.

33 Sato N, Kitahara T, Fujimura T: Age-related changes of stratum corneum functions of skin on the trunk and the limbs. Skin Pharmacol Physiol 2014;27:181.

34 Jungersted JM, Scheer H, Mempel M, Baurecht $\mathrm{H}$, Cifuentes L, Hogh JK, Hellgren LI, Jemec GB, Agner T, Weidinger S: Stratum corneum lipids, skin barrier function and filaggrin mutations in patients with atopic eczema. Allergy 2010;65:911-918.

35 Nemoto-Hasebe I, Akiyama M, Nomura T, Sandilands A, McLean WH, Shimizu H: Clinical severity correlates with impaired barrier in filaggrin-related eczema. J Invest Dermatol 2009;129:682-689.
36 Janssens M, van Smeden J, Gooris GS, Bras W, Portale G, Caspers PJ, Vreeken RJ, Hankemeier T, Kezic S, Wolterbeek R, Lavrijsen AP, Bouwstra JA: Increase in short-chain ceramides correlates with an altered lipid organization and decreased barrier function in atopic eczema patients. J Lipid Res 2012;53:27552766.

37 Huang HC, Chang TM: Ceramide 1 and ceramide 3 act synergistically on skin hydration and the transepidermal water loss of sodium lauryl sulfate-irritated skin. Int J Dermatol 2008;47:812-819.

38 Gloor M, Fluhr J, Lehmann L, Gehring W, Thieroff-Ekerdt R: Do urea/ammonium lactate combinations achieve better skin protection and hydration than either component alone? Skin Pharmacol Appl Skin Physiol 2002; 15:35-43.

39 Pan M, Heinecke G, Bernardo S, Tsui C, Levitt J: Urea: a comprehensive review of the clinical literature. Dermatol Online J 2013;19: 20392.

40 Loden M: The use of urea in the treatment of dry skin; in Loden M, Maibach H (eds): Treatment of Dry Skin Syndrome: The Art and Science of Moisturizers. Berlin, Springer, 2012, pp 481-492.

41 Hagemann I, Proksch E: Topical treatment by urea reduces epidermal hyperproliferation and induces differentiation in psoriasis. Acta Derm Venereol 1996;76:353-356.

42 Rawlings A, Harding C, Watkinson A, Banks J, Ackerman C, Sabin R: The effect of glycerol and humidity on desmosome degradation in stratum corneum. Arch Dermatol Res 1995; 287:457-464.

43 Schmid-Wendtner MH, Korting HC: The pH of the skin surface and its impact on the barrier function. Skin Pharmacol Physiol 2006; 19:296-302.

44 Grether-Beck S, Felsner I, Brenden H, Kohne Z, Majora M, Marini A, Jaenicke T, Rodriguez-Martin M, Trullas C, Hupe M, Elias PM, Krutmann J: Urea uptake enhances barrier function and antimicrobial defense in humans by regulating epidermal gene expression. J Invest Dermatol 2012;132:1561-1572.

45 Loden M: Urea-containing moisturizers influence barrier properties of normal skin. Arch Dermatol Res 1996;288:103-107.

46 Loden M, Andersson AC, Lindberg M: Improvement in skin barrier function in patients with atopic dermatitis after treatment with a moisturizing cream (Canoderm). Br J Dermatol 1999;140:264-267.

47 Loden M, Wiren K, Smerud KT, Meland N, Honnas H, Mork G, Lutzow-Holm C, Funk J, Meding B: The effect of a corticosteroid cream and a barrier-strengthening moisturizer in hand eczema. A double-blind, randomized, prospective, parallel group clinical trial. J Eur Acad Dermatol Venereol 2012;26:597-601.
48 Loden M, Wiren K, Smerud K, Meland N, Honnas H, Mork G, Lutzow-Holm C, Funk J, Meding B: Treatment with a barrier-strengthening moisturizer prevents relapse of handeczema. An open, randomized, prospective, parallel group study. Acta Derm Venereol 2010;90:602-606.

49 Akerstrom U, Reitamo S, Langeland T, Berg M, Rustad L, Korhonen L, Loden M, Wiren K, Grande M, Skare P, Svensson A: Comparison of moisturizing creams for the prevention of atopic dermatitis relapse: a randomized double-blind controlled multicentre clinical trial. Acta Derm Venereol 2015;95:587-592.

50 Rawlings AV, Davies A, Carlomusto M, Pillai S, Zhang K, Kosturko R, Verdejo P, Feinberg C, Nguyen L, Chandar P: Effect of lactic acid isomers on keratinocyte ceramide synthesis, stratum corneum lipid levels and stratum corneum barrier function. Arch Dermatol Res 1996;288:383-390.

51 Gooris GS, Bouwstra JA: Infrared spectroscopic study of stratum corneum model membranes prepared from human ceramides, cholesterol, and fatty acids. Biophys J 2007;92:2785-2795.

52 Luebberding S, Krueger N, Kerscher M: Skin physiology in men and women: in vivo evaluation of 300 people including TEWL, SC hydration, sebum content and skin surface $\mathrm{pH}$. Int J Cosmet Sci 2013;35:477-483.

53 O'Regan GM, Kemperman PM, Sandilands A, Chen H, Campbell LE, Kroboth K, Watson R, Rowland M, Puppels GJ, McLean WH, Caspers PJ, Irvine AD: Raman profiles of the stratum corneum define 3 filaggrin genotypedetermined atopic dermatitis endophenotypes. J Allergy Clin Immunol 2010;126:574580.

54 Sugawara T, Kikuchi K, Tagami H, Aiba S, Sakai S: Decreased lactate and potassium levels in natural moisturizing factor from the stratum corneum of mild atopic dermatitis patients are involved with the reduced hydration state. J Dermatol Sci 2012;66:154-159.

55 Kezic S, Kammeyer A, Calkoen F, Fluhr JW, Bos JD: Natural moisturizing factor components in the stratum corneum as biomarkers of filaggrin genotype: evaluation of minimally invasive methods. Br J Dermatol 2009;161: 1098-1104.

56 Mark H, Harding CR: Amino acid composition, including key derivatives of eccrine sweat: potential biomarkers of certain atopic skin conditions. Int J Cosmet Sci 2013;35: 163-168.

57 Elias PM: Lipid abnormalities and lipid-based repair strategies in atopic dermatitis. Biochim Biophys Acta 2014;1841:323-330. 